\title{
An evidence-based data set on climate changes for developing countries
}

\author{
Luc Hens
}

Received: 21 October 2013/Accepted: 19 November 2013/Published online: 22 December 2013

(C) Springer Science+Business Media Dordrecht 2013

On Friday September 27th, 2013, the World Meteorological Organization (WMO) and the United Nations Environment Programme (UNEP) launched the first part of the Fifth Assessment Report (AR5) of the United Nations Intergovernmental Panel on Climate Change (IPCC). The document on "The physical science basis" of climate changes (CC) is the first one in a series of four, which will constitute AR5. To be published in 2014 are two reports dealing with impacts, adaptation, mitigation, vulnerability plus a synthesis report. As before, the publication presents the scientific consensus (258 experts are involved in the "Scientific basis" report; AR5 involves 831 specialists worldwide) allowing the assessment of 9,200 scientific and technical publications on climate change.

The results of the current assessment confirm, update and specify the work of the four previous status evaluations. Main headlines of these results entail:

- Warming of the atmosphere and the oceans is unequivocal. The warming of the upper ocean layers accounts for $90 \%$ of the heat accumulation.

- A clear human influence on the climate exists. This human influence is a dominant cause of the warming since the 1950s.

- It is likely that 1983-2013 was the warmest 30 years period for 1,400 years.

- Mountainous, Arctic and Antarctic ice sheets have been losing mass during the last two decades.

- Sea level is rising.

- Further warming will continue if emissions of greenhouse gasses (GHG) build up. By the end of this century, a fork of temperature rise between 1.5 and $4.5^{\circ} \mathrm{C}$ is now the forecast.

- Oceans will continue warming up, the sea level rises and the sea surface acidifies as a result of the absorption of $\mathrm{CO}_{2}$.

No doubt the publication of this first section of AR5 and the statement that scientists are "certain" that manmade CC is ongoing will affirm the worldwide attention for the subject.

L. Hens (ه)

Vlaamse Instelling voor Technologisch Onderzoek (VITO), Laarbeeklaan 103, 1090 Brussels, Belgium e-mail: luchens51@gmail.com 
On the other hand, also the deniers of $\mathrm{CC}$ and the lobbyists for a "business as usual action," as those of the coal and the oil sectors, will find new arguments in this report. They will fuel uncertainty and criticism. Therefore, it is uncertain whether after the Copenhagen 2009 debacle, where the negotiations for a global CC treaty collapsed, this report will revive the political will to curb carbon and related GHG emissions. One might expect that this report will hardly influence politicians starting to listen to the scientific arguments and conclusions on CC.

The current report provides mainly a worldwide assessment. It offers hardly regional or country-specific data. This applies also to developing countries (DC). On the other hand, every country is responsible for the emission of the GHG on its own territory. Industrialized countries have a greater share in the responsibilities than developing countries. However, if the next section of AR5 confirms that developing lowland countries as central Vietnam and Bangladesh will experience the effects (e.g., on drought and sea level rise) more intense than rich countries; this will also mean specific duties, legitimate expectations and actions in DC. One of them requires more research and studies on the causes, effects and replies to $\mathrm{CC}$ in DC, and more evidence-based science and policy in "the South" which calls worldwide for more and better research on the subject.

"Environment, Development and Sustainability" aims at contributing to alleviating this pressing need. Part of our editorial policy is giving priority to the publication of review and research papers contributing to the scientific evidence base for the most needed CC curb, which, according to the first part of AR5, is now more necessary than ever before. More in particular, this is a call for papers on livestock and biomass production (among others for biofuels). This strategy is complementary to our aim to continue publishing papers on other pressing global environmental issues as human population growth, starvation and the use of environmental assets. 